\title{
ESPAÇOS ARQUITETÔNICOS PARA AUTISTAS - ESTUDO DE CASO: INSTITUIÇÃO LUMEN ET FIDES
}

Yasmin Miranda Perosso, Yeda Ruiz Maria, Maury Vieira de Jesus

Universidade do Oeste Paulista - UNOESTE, curso de Arquitetura e Urbanismo, Presidente Prudente, SP. E-mail: yedarm@hotmail.com

\section{RESUMO}

O presente trabalho aborda os espaços arquitetônicos destinados a pessoas com Transtorno do Espectro Autista. Os autistas possuem uma percepção diferenciada dos ambientes que frequentam, pois possuem uma sensibilidade extrema em relação a audição, visão e tato, assim. Esta pesquisa busca fazer considerações a respeito de como os ambientes podem ser elaborados e organizados de forma a atender as necessidades dos usuários ao mesmo tempo em que proporcionem conforto e estímulos sensoriais para colaborar no desenvolvimento dos autistas. A importância desta pesquisa é justificada pela necessidade de estruturar e adequar os espaços a estes usuários e a metodologia adotada foi de levantamentos bibliográficos e levantamentos in loco da instituição Lumen et Fides.

Palavras-chave: arquitetura; autismo; conforto ambiental; Lumen et Fides; estímulos sensoriais.

\section{ARCHITECTURAL SPACES FOR AUTISTIC PERSONS - CASE STUDY OF THE INSTITUTION LUMEN ET FIDES}

\begin{abstract}
The present work boards the architectural spaces destined to persons with Upset of the Autistic Specter. The autistic persons have a differentiated perception of the environments that they frequent, since they have an extreme sensibility regarding audition, vision and touch, so, this inquiry looks to do considerations as to as the environments can be prepared and organized in the form attending the necessities of the users at the same time in which they provide comfort and sensory stimuli to contribute to the development of the autistic persons. The importance of this inquiry is justified by the necessity of structuring and of adapting the spaces to these users and the adopted methodology was of bibliographical liftings and liftings in loco of the institution Lumen et Fides.
\end{abstract}

Keywords: architecture; autism; environmental comfort; Lumen et Fides; sensory stimuli.

\section{INTRODUÇÃO}

O Transtorno do Espectro Autista se caracteriza por uma desordem no desenvolvimento que ocasiona comportamento estereotipado e prejuízos na comunicação e interação social (ALVES, COUTINHO, MENEZES, 2009, p.83).

A arquitetura tende a colaborar no atendimento dos autistas por meio da estruturação dos espaços de acordo com as necessidades dos usuários, viabilizando através de soluções arquitetônicas, ambientes confortáveis e propícios a serem explorados, aumentando o desempenho dos indivíduos e se tornando fonte de evolução no tratamento (HENRY, 2011).

Dessa forma, compreendendo as características gerais que as pessoas com Transtorno do Espectro Autista apresentam é necessário se atentar ao espaço que os acolhem e possibilitem o atendimento e tratamento, pois, como Góes (2010, p. 39) afirma, a maior parte das instituições 
atuais "trabalham mais sobre a metodologia do tratamento. A questão espacial raramente é enfatizada ou mesmo mencionada."

Alves, Coutinho e Menezes (2009) indicam que faltam recursos relacionados a comunicação alternativa e a estruturação do ambiente para compreensão dos autistas sobre atividades diárias e que é preciso desenvolver estudos que busquem suprir essa carência e favorecer a autonomia dessas pessoas.

Os espaços projetados para autistas devem ser dotados de estrutura flexível que possibilite a assistência a todos os indivíduos, do grau mais ameno até o mais elevado, sendo adaptados de acordo com as necessidades dos usuários, permitindo atendimento especifico, além de trabalhar principalmente as áreas da comunicação e do comportamento.

Assim, o objetivo geral deste trabalho é discutir os espaços arquitetônicos para autistas, apresentando soluções arquitetônicas que colaborem no desenvolvimento e organização de ambientes para que estes proporcionem maior conforto aos usuários e assim favoreçam um maior desempenho intelectual e físico, tendo como objeto de estudo a instituição Lumen et Fides, que teve seu projeto avaliado e relacionado aos padrões da boa arquitetura.

A metodologia utilizada neste artigo foi desenvolvida através de investigação qualitativa, fazendo uso de levantamentos bibliográficos e de levantamentos arquitetônicos in loco da instituição Lumen et Fides de Presidente Prudente - SP.

$\mathrm{Na}$ primeira etapa, de levantamentos bibliográficos, foram consultados trabalhos de conclusão de curso, monografias, dissertações, teses, periódicos e livros pertinentes ao tema proposto.

Em seguida, foi feito análise da instituição Lumen et Fides, através de levantamentos métricos e fotográficos in loco, para obtenção da percepção dos espaços e fluxos do edifício.

\section{ESPAÇOS ARQUITETÔNICOS PARA AUTISTAS}

Projetar para autistas é um grande desafio, visto que nem a medicina ainda desvendou os elementos teóricos e metodológicos que possibilitem o entendimento da mente dessas pessoas, logo, faltam critérios e padrões arquitetônicos para o dimensionamento e a determinação dos aspectos ideais de cada espaço (GÓES, 2010).

Góes (2010) enfatiza que há infinitas possibilidades de forma espacial e mesmo sem os parâmetros para a elaboração de um projeto arquitetônico. Freire (2005, p.142) defende que "[...] o ambiente deve se adequar ao aluno e não o inverso, na medida em que é fundamental termos alguns cuidados especiais quanto a disposição do mobiliário, tipo de material a ser usado etc."

A percepção dos espaços pelos autistas é diferente da percepção das pessoas não autistas, assim como não há padrões dentro de cada grau do espectro, sendo distinta de um portador para o outro. Os cuidados com a estimulação sensorial são importantes, pois eles possuem uma sensibilidade muito maior à luz, cores, texturas e sons, além de que devido às dificuldades em processar e organizar informações.

Assim como outros estabelecimentos que prestam serviços de assistência à saúde, nos destinados aos autistas é necessário, durante a elaboração do projeto arquitetônico, uma atenção especial aos elementos ambientais que proporcionem conforto ambiental (acústico, visual, higrotérmico, olfativo e ergonômico), pois estes ambientes podem causar situações estressantes e críticas relacionados aos graus de sofrimento físico e/ou psíquico dos usuários (BRASIL, 2014).

Brasil (2014) dispõe algumas soluções sustentáveis, que quando aplicadas no edifício, auxiliam na obtenção do conforto ambiental. Entre elas se encontra para a redução de temperatura nos ambientes internos o uso de ventilação natural, telhados verdes, brises soleil (quebra-sol) e espelhos d'agua; o uso de vegetação para diminuição de ruídos e também de temperaturas; e a utilização de energia solar como energia elétrica e para aquecimento da água. Blower e Azevedo (2008) ainda recomendam que a edificação deve ser implantada considerando o 
norte e seguindo uma orientação adequada, também indicam a utilização de pés-direitos altos para uma boa circulação de ar, a utilização de ventilação cruzada, o uso de materiais construtivos isolantes e pátios internos arborizados.

De acordo com Lukiantchuki e Caram (2008), a iluminação e ventilação naturais são muito utilizadas na humanização dos ambientes internos, uma vez que auxiliam no tratamento à medida que melhoram as condições térmicas, visuais e higiênicas.

Para a Brasil (2014), o paisagismo também faz parte da humanização dos ambientes e é extremamente importante pois a vegetação influencia no psicológico das pessoas reduzindo o estresse, além de que não contribui somente para a estética da paisagem, mas auxilia no conforto acústico diminuindo os ruídos do local e também na qualidade climática da edificação no todo, pois através dele é possível sombrear áreas e também administrar a trajetória dos ventos, possibilitando ventilação em toda a edificação.

Em relação ao conforto acústico, é possível afirmar que "a aplicação dos princípios da acústica arquitetônica ao projeto de ambientes de saúde devem evitar os ruídos ou a reverberação do som, tanto para os pacientes quanto para os profissionais que atuam nesses espaços" (BRASIL, 2014, p. 56). Assim, o arquiteto deve procurar soluções que partem da forma e da implantação da edificação, até a escolha dos materiais de revestimento para amenizar o desconforto acústico provocado pelos ruídos (BRASIL, 2014).

Outro item a ser considerado é o conforto visual, proporcionado através do uso das cores e da iluminação, com o objetivo de facilitar o desenvolvimento de atividades (BRASIL, 2014). De acordo com Mueller (2007, p.57) "o ambiente visual é agradável de se ver, de se sentir e de nele se encontrar. Ele é acolhedor, luminoso; é influenciado pelo espaço que o circunda e pela possibilidade de vistas para o exterior; é composto por cores, superfícies, materiais, texturas e revestimentos que o enriquecem."

Algumas recomendações gerais sobre os locais especializados são propostas por Góes (2010), onde o autor indica que os espaços projetados devem apresentar semelhança com os locais que habitualmente são vivenciados pelos autistas, assim como devem apresentar claramente seus usos.

Góes (2010) ainda recomenda a utilização de diversos materiais que provoquem sensações diferentes no campo visual e tátil, como também a utilização de diversas cores na paginação dos locais por favorecer a orientação.

Por fim, ressalta-se também que em local especializado no atendimento a pessoas com Transtorno do Espectro Autista é essencial e indispensável seguir as recomendações da NBR 9050/2014, pois pela Lei Federal $n^{\circ} 12.764 / 2012$, os autistas são considerados deficientes, sendo assim, necessitam de espaços acessíveis e adequados.

\section{A INSTITUIÇÃO LUMEN ET FIDES}

A Lumen et Fides é uma instituição filantrópica localizada na cidade de Presidente Prudente - SP, no bairro Jardim da Boa Vista, que atende pessoas de todas as idades diagnosticadas com disfunções neuromotoras, doenças neuromusculares e Transtorno do Espectro Autista, oferecendo tratamento especializado com multiprofissionais nas áreas de fisioterapia, fonoaudiologia, psicologia, serviço social, terapia ocupacional, nutrição e pedagogia, onde adotam os métodos de ensino TEACCH e Currículo Funcional Natural.

Em visitas in loco, a atual coordenadora da equipe de saúde, Luciana Christine F. Tanaka e a diretora pedagógica Perlla Cristina R. Oliveira relataram que atualmente a entidade atendem um total de 155 pacientes, sendo que destes, 55 são autistas, tratados em um setor especifico com capacidade física para 50 atendidos, existindo ainda uma lista de espera de 45 pessoas já diagnosticadas com Transtorno do Espectro Autista. 
A instituição tem seu programa de necessidades organizado em quatro blocos e possui três acessos, sendo que o acesso principal acontece pela fachada frontal, voltada para a Rua Maria Fernandes.

Por se tratar de uma instituição que envolve saúde e educação, o complexo é cercado por alambrado, o que garante uma relação com o entorno através da permeabilidade visual. A entrada de pessoas é restrita, devendo ser autorizada por algum funcionário, por isso, o acesso principal funciona como uma entrada social e direciona quem chega primeiramente a recepção para que só depois da autorização possa ter acesso aos outros ambientes. Já os acessos secundários só podem ser utilizados por funcionários, pais e atendidos, pois permitem acesso direto as dependências da entidade.

Os blocos foram implantados de acordo com a verba disponível e as necessidades que surgiram ao longo do tempo, o que ocasionou construções e reformas sem planejamento adequado. Dentre os quatro blocos, apenas dois são interligados diretamente por meio de uma cobertura metálica sustentada por pilares metálicos, enquanto os outros se encontram a uma distância considerável e não possuem conexão com as outras edificações, não dispondo de caminho pavimentado, indicando o percurso e nem cobertura que proteja os usuários de intempéries.

Assim como a cobertura que interliga os dois blocos, os edifícios possuem cobertura metálica, são pintados nas cores branco, amarelo e azul e foram construídos em alvenaria, sendo que em três deles foram utilizados blocos de concreto e em apenas um, o que abriga o setor de apoio familiar, foram utilizados tijolos de barro.

Os blocos são divididos por setores (Figura 1) que foram definidos pela proximidade dos ambientes que possuem tipologias iguais ou parecidas.

Figura 1 - Planta baixa setorizada por setores - sem escala.

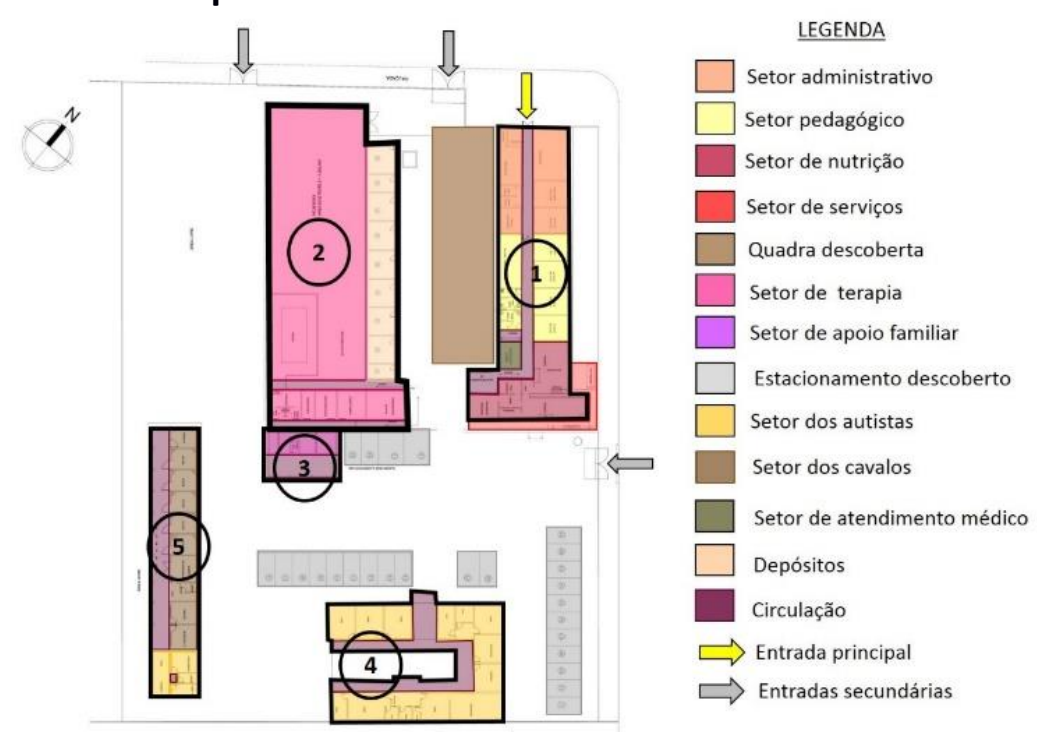

Fonte: Autora, 2017

Assim, tem-se os setores administrativo, pedagógico, de nutrição, de serviço, de terapia, de atendimento médico, de apoio familiar, dos autistas, da equoterapia e também quadra descoberta, depósitos e estacionamento.

Apesar de amplas janelas, que proporcionam iluminação e ventilação natural, estas não são suficientes para proporcionar conforto térmico para os edifícios, já que as telhas metálicas absorvem calor e tornam o bloco extremamente quente. 
O bloco dos autistas possui o formato em " $U$ " e abriga espaços para o aprendizado e para terapias que junto com a casa do autista forma um conjunto separado por alambrado do restante da instituição, para evitar a fuga de autistas.

Como já dito, a instituição atende deficientes e neste caso, um aspecto importantíssimo para a garantia da mobilidade em suas dependências é a acessibilidade, que pode ser considerada deficitária por dois motivos visíveis.

O primeiro motivo, diz respeito a interligação dos blocos da frente com os blocos que se localizam mais ao fundo do lote, onde não há caminhos adequados, pois, este percurso é feito pelo estacionamento que é coberto por pedras, o que dificulta a passagem. O segundo motivo é que visivelmente as rampas de acesso aos setores da terapia e da pedagogia não atendem a inclinação de 8,33\% exigida pela NBR 9050 referente a acessibilidade.

As deficiências arquitetônicas são visíveis, porém vale pontuar que na Lumen et Fides os pacientes recebem um atendimento humanizado e muito eficaz, obtendo um desenvolvimento excepcional. Destaca-se ainda que este atendimento obtém êxito mesmo com as dificuldades encontradas na ambientação atual do recinto, como a falta de acessibilidade e de conforto térmico.

\section{CONSIDERAÇÕES FINAIS}

As instalações da Lumen et Fides não cumprem as necessidades básicas do conforto ambiental que garantiriam um melhor desempenho aos seus usuários. Dentre os problemas arquitetônicos contatados estão a implantação dos edifícios sem preocupação com a orientação solar, a acessibilidade precária, a falta de soluções relacionadas a humanização dos ambientes, como pouco aproveitamento da iluminação e ventilação natural, pouca utilização de cores e de recursos para a proteção da luz solar excessiva, e a falta de paisagismo. Destaca-se que alguns destes problemas podem ser facilmente resolvidos com a realização de um projeto de (re)adequação.

\section{REFERÊNCIAS BIBLIOGRÁFICAS}

ALVES, S. G.; COUTINHO F. A.; MENEZES, A. B. A estruturação do ambiente para a pessoa com autismo: Um relato de experiência. Pedagogia em ação, Belo Horizonte, vol.1, n.2, 2009. p.7986. ISSN 2175-7003. Disponível em: <http://periodicos.pucminas.br/index.php/pedagogiacao/article/view/1085/1118> Acesso em 29 set. 2016.

BRASIL, Agência Nacional de Vigilância Sanitária. Conforto Ambiental em Estabelecimentos Assistenciais de Saúde: Agência Nacional de Vigilância Sanitária. Brasília: Agência Nacional de Vigilância Sanitária, 2014. Disponível em: <http://conforlab.com.br/legislacao/manual_conforto_ambiental.pdf>. Acesso em 14 abr. 2017.

BLOWER, H. C. S.; AZEVEDO, G. A. N. A Influência do Conforto Ambiental na Concepção da Unidade de Educação Infantil: Uma Visão Multidisciplinar. In: Espaço Sustentável: inovações em edifícios e cidades, 7., 2008, São Paulo. Anais eletrônicos de conforto ambiental e sustentabilidade, São Paulo: NUTAU, 2008. Disponível em: < https://www.usp.br/nutau/CD/index.html>. Acesso em: 05 abr. 2017.

FREIRE, L. H. V. Formando Professores. In: CAMARGO JR., W. et al. Transtornos invasivos do desenvolvimento: $3^{\circ}$ Milênio. 2 ed. Brasília: CORDE, 2005. v.2. p. 138-143. Disponível em: < http://www.pessoacomdeficiencia.gov.br/app/publicacoes/transtornos-invasivos-dodesenvolvimento-3-milenio>. Acesso em: 24 abr. 2017. 
GÓES, R. Manual prático de arquitetura para clínicas e laboratórios. $2^{\circ}$ ed. rev. e ampl. São Paulo: Bucher, 2010.

HENRY, Christopher N. Designing for Autism: Spatial Considerations. 2011. ArchDaily. Disponível em: < http://www.archdaily.com/179359/designing-for-autism-spatial-considerations>. Acesso: em 09 mar. 2017.

MUELLER, C. M. Espaços de ensino-aprendizagem com qualidade ambiental: 0 processo metodológico para elaboração de um anteprojeto. 2007. 258 f. Dissertação (Mestrado em Tecnologia da Arquitetura) - Universidade de São Paulo, São Paulo - $\quad$ SP. $\quad$ Disponível em: < http://www.teses.usp.br/teses/disponiveis/16/16132/tde-19092007-142731/pt-br.php>. Acesso em: 16 abr. 2017. 